TITLE:

\title{
Sexual Size Dimorphism and Aggressive Interactions under Starvation Conditions in the Seed Bug Togo hemipterus (Heteroptera: Lygaeidae)
}

\section{AUTHOR(S):}

Himuro, Chihiro; Fujisaki, Kenji

\section{CITATION:}

Himuro, Chihiro ...[et al]. Sexual Size Dimorphism and Aggressive Interactions under Starvation Conditions in the Seed Bug Togo hemipterus (Heteroptera: Lygaeidae). Journal of Insect Behavior 2012, 25(3): 242-253

\section{ISSUE DATE:}

2012-05

URL:

http://hdl.handle.net/2433/154896

\section{RIGHT:}

The final publication is available at www.springerlink.com; この論文は 出版社版でありません。引用の際には出版社版をご確認ご利用くださ $\omega_{\circ}$; This is not the published version. Please cite only the published version. 


\section{Editorial Manager(tm) for Journal of Insect Behavior Manuscript Draft}

Manuscript Number:

Title: Sexual Size Dimorphism and Aggressive Interactions under Starvation Conditions in the Seed Bug Togo hemipterus (Heteroptera: Lygaeidae)

Article Type: Original Research

Keywords: sexual size dimorphism; aggressive behavior; starvation conditions; resource-defense mating system; male body size; Togo hemipterus

Corresponding Author: Chihiro Himuro

Corresponding Author's Institution:

First Author: Chihiro Himuro

Order of Authors: Chihiro Himuro;Kenji Fujisaki, Professor

Abstract: Males of the seed bug Togo hemipterus are larger in size and have considerably larger front legs compared to females. This size discrepancy is likely related to the fact that males fight for food using their enlarged forelegs. A "hungry" bug, i.e. one previously without food, is expected to behave in a certain way when food is present. Here, we demonstrate that aggressive "fighting and chasing" behavior was frequently observed only between males under starvation conditions and became especially severe when food was present. Togo hemipterus males may adopt a resource-defense mating system that is beneficial for males because females aggregate near food when it is scarce. This strategy strongly suggests that the aggressive behavior acts as male-male competition. In a second set of experiments, aggressive behavior occurred between two small males, two large males, or one large and one small male. Fighting ensued mainly when large males were involved, and larger males won fights. Consequently, the male-biased sexual size dimorphism in T. hemipterus appears to be partially attributable to sexual selection favoring larger males. 
Sexual Size Dimorphism and Aggressive Interactions under Starvation Conditions in the Seed Bug Togo hemipterus (Heteroptera: Lygaeidae)

$$
\text { Chihiro Himuro }^{1,2, \dagger} \text { and Kenji Fujisaki }{ }^{1}
$$

${ }^{1}$ Laboratory of Insect Ecology, Graduate School of Agriculture, Kyoto University, Kyoto, Japan

${ }^{2}$ To whom correspondence should be addressed: Laboratory of Insect Ecology, Graduate

School of Agriculture, Kyoto University, Oiwakechou, Kitashirakawa, Sakyo-ku, Kyoto, 606-8502, Japan. Tel: +81-75-753-6147. Fax: +81-75-753-6474. E-mail:

chimuro@kais.kyoto-u.ac.jp

${ }^{\dagger}$ Present address: Laboratory of Insect Ecology, Graduate School of Environmental

Science, Okayama University, 1-1-1 Tsushima-naka, Kita-ku, Okayama, 700-8530, Japan.

Tel \& Fax: +81-86-251-8379.

Running head: Sexual size dimorphism and male aggressive behavior in the seed bug 


\begin{abstract}
Males of the seed bug Togo hemipterus are larger in size and have considerably larger front legs compared to females. This size discrepancy is likely related to the fact that males fight for food using their enlarged forelegs. A "hungry" bug, i.e. one previously
\end{abstract}

5 without food, is expected to behave in a certain way when food is present. Here, we demonstrate that aggressive "fighting and chasing" behavior was frequently observed only between males under starvation conditions and became especially severe when food was present. Togo hemipterus males may adopt a resource-defense mating system that is beneficial for males because females aggregate near food when it is scarce. This

10 strategy strongly suggests that the aggressive behavior acts as male-male competition. In a second set of experiments, aggressive behavior occurred between two small males, two large males, or one large and one small male. Fighting ensued mainly when large males were involved, and larger males won fights. Consequently, the male-biased sexual size dimorphism in T. hemipterus appears to be partially attributable to sexual selection 15 favoring larger males. 
KEY WORDS: sexual size dimorphism; aggressive behavior; starvation conditions;

resource-defense mating system; male body size; Togo hemipterus

\section{INTRODUCTION}

Many animals compete for limited resources, such as food, oviposition sites, mating sites, and mates, especially among males (reviewed in Thornhill and Alcock 1983; Andersson 1994). Consequently, males have developed various distinct traits as

25 "weapons" for use in male-male competition. Such weapons are observed in many animal taxa, from invertebrates to vertebrates (reviewed in Andersson 1994). Insects in particular have developed many distinct weapons, such as the long horn of horned beetles (Eberhard 1979, 1980; Otte and Stayman 1979; Burkhardt and de la Motte 1988), the enlarged mandibles of stag beetles (Otte and Stayman 1979), the long eye stalks of stalk-eyed flies (McAlpine 1979; Burkhardt and de la Motte 1988; Wilkinson and Dodson 1997), and the enlarged forceps of earwigs (Moore and Wilson 1993; Radesäter and Halldórsdóttir 1993; Forslund 2000). Such traits often exhibit strong sexual 
dimorphism, and females usually have smaller or rudimentary traits (reviewed in Thornhill and Alcock 1983; Eberhard and Gutiérrez 1991; Andersson 1994; Emlen and Nijhout 2000). Larger males with more developed traits are directly favored in male-male competition (reviewed in Thornhill and Alcock 1983; Andersson 1994).

Some species of Heteroptera have weapons that serve in male-male competition for limited resources. Some coreids have enlarged and spiny femora on the hind legs (Miller, 1971) while in some lygaeids similar morphological characteristics are seen on femor of

40 the forelegs (Schuh and Slater 1995; Rodriguez 2000). In the case of coreids they are used in male-male interactions (Fujisaki 1980, 1981; Mitchell 1980; Miyatake 1993, 1995, 1997; Eberhard 1998), while Rodriguez (2000) noted in the lygaid Scolopostethus affinis both sexes could use the front legs to strike opponents although such aggressive interactions were rare. contestants differ in fighting ability or resource-holding power, this asymmetry, if perceived by both contestants, should be used to settle contests. Escalated fighting should occur when the difference in the size of contestants is small (Maynard Smith and 
Price 1973), and many studies have verified this hypothesis (e.g. Austad 1983; Wells

We hypothesized that food may have a strong effect on competition in the Lygaeidae, as they rarely display aggression when food is absent and only exhibit such behavior when food is present (Himuro, unpublished data). If the presence of food is a key cause of competition, a "hungry" bug, i.e. one previously without food, is expected to behave in a certain way when food is present, and the level of starvation should influence the strength of aggression. Preliminary observations have indicated that the seed bug Togo hemipterus (Scott) exhibits two types of aggressive behavior: indirect (chasing) and direct (fighting). In chasing behavior, one individual chases another while shaking its own antennae. In fighting behavior, two individuals stand on their middle and hind legs; raise their head, thorax, and forelegs; extend their forelegs horizontally; and strike each other with the forelegs while shaking their antennae, similar to observations of other lygaeids (e.g. Rodriguez 2000). They are ground-living and feed on gramineous seeds such as Oryza sativa (L.), Digitaria ciliaris (Retz), and Setaria viridis (L.) (Tomokuni et al. 1993). 
enlarged forelegs have developed mainly through sexual selection. Second, we expect that aggressive behavior occurs mainly between males, the purpose of which is to acquire mates and is mediated by the presence of food. Therefore, we first examined the sexual size dimorphism of the forelegs and observed aggressive behavior between males, between females, and between males and females under two levels of starvation (starved for 0 or 10 days). In addition, we examined the effect of body size as an index of resource-holding power on aggressive behavior and the outcome of contests. We sought to determine why these individuals fight and to identify the main context of aggressive behavior.

\section{MATERIALS AND METHODS}

Insect Rearing

Adults of T. hemipterus were originally derived from wild females collected on the campus of Kyoto University, Kyoto, western Japan $\left(35^{\circ} 01^{\prime} \mathrm{N}, 135^{\circ} 46^{\prime} \mathrm{E}\right)$, on $21-22$ 
that contained moist sand to maintain suitable humidity; the openings were covered with nylon mesh. We provided distilled water and fresh brown rice as food every $4-5$ days for all developmental stages of bugs. The bugs were maintained under a photoperiod of $16 \mathrm{~h}$ light:8 h dark (light: 07:00-23:00 h) at $25 \pm 2{ }^{\circ} \mathrm{C}$. After imaginal molt and cuticular 85 hardening, i.e. after the insect's body coloration blackened, we transferred bugs to jars (0.43 L) with wet cotton and brown rice. Five days later, we segregated bugs by sex to prevent mating prior to experiments. Individuals of the same sex and age were housed together for 20 days, with no more than five individuals per jar. Adult bugs were individually marked with a paint marker (Mitsubishi Paint Marker PX-21, Mitsubishi

90 Pencil Co., Ltd., Japan), and body length was measured using a stereomicroscope equipped with an ocular micrometer. The pre-reproductive period of this species is approximately 25 days at $25^{\circ} \mathrm{C}$; reproductive activity then continues for approximately 3 months (Himuro, unpublished data). In all experiments, we used sexually mature virgin individuals.

Sexual Size Dimorphism of Morphometric Traits 
To compare the morphometric traits of adult male and female T. hemipterus, we collected adults on the campus of Kyoto University on 16, 17, 30 April and 1 May 2002 and measured the morphometric traits of 254 males and 259 females. Measured parameters included body length (i.e. from the top of the head to the tip of the abdomen: as a indicator of body size), pronotum width, femur length and width of the right foreleg, and femur length of the right middle leg. If right legs were absent, we measured left legs.

Differences in Aggressive Behavior and Effects of Starvation by Sex dishes containing wet cotton and two grains of brown rice. On the following day, we removed the rice and starved the individuals for 0 or 10 days. The 10 -day starvation period had no debilitating effect on T. hemipterus (Himuro, unpublished data). To examine aggressive behavior between males, between females, and between males and

110 females, we placed two males and two females in a Petri dish $(90 \mathrm{~mm}$ diameter, $20 \mathrm{~mm}$ depth) with one grain of brown rice and used a digital video camera (SONY DCR-PC120 NTSC, Sony Corporation, Japan) to record their behavior for $2 \mathrm{~h}$ 
(10:00-12:00) under constant fluorescent light at $25 \pm 2^{\circ} \mathrm{C}$ (starved for 0 days, $N=11$;

10 days, $N=13$ ). We examined the proportion of individuals that displayed aggressive

115 behavior (chasing and/or fighting) and the proportion of successfully feeding individuals

(the proportion of individuals that were able to feed on the grain of brown rice with no aggressive behavior under the control of a male).

Male Aggressive Behavior and Effects of Starvation and Body Size

120 The body length of field-collected males was $5.94 \pm 0.02 \mathrm{~mm}($ mean $\pm 1 \mathrm{SE}, N=254)$

and ranged from 4.97 to $6.80 \mathrm{~mm}$, with a unimodal distribution. For the purposes of subsequent experiments testing the effect of relative size, we regarded males with body lengths of $6.2-6.5 \mathrm{~mm}$ as large and those of 5.3-5.6 $\mathrm{mm}$ as small.

Two males were placed in a Petri dish (45 mm diameter, $20 \mathrm{~mm}$ depth) with one grain of brown rice, and their behavior was recorded for $2 \mathrm{~h}(10: 00-12: 00)$ with same procedures mentioned above. Three types of experiments were performed on bugs that had been previously subjected to three different food regimes (starved for 0,5 , or 10 days). First, two small males were used to examine aggressive behavior between small 
males (starved for 0 days, $N=16 ; 5$ days, $N=13 ; 10$ days, $N=13$ ). Second, two large males were used to examine aggressive behavior between large males (starved for 0 days, $N=14 ; 5$ days, $N=16 ; 10$ days, $N=16$ ). Finally, one large male and one small male were used to examine aggressive behavior between small and large males (starved for 0 days, $N=14 ; 5$ days, $N=13 ; 10$ days, $N=16$ ). We measured the proportion of individuals that chased and fought, the frequency of chasing and fighting behavior, the

135 duration of fighting, and the outcome of chasing and fighting.

Which Is the Main Factor Causing Male Aggressive Behavior: Food or Female?

Two males that had been starved for 10 days were placed in a Petri dish $(45 \mathrm{~mm}$ diameter, $20 \mathrm{~mm}$ depth) and their behavior was recorded for $2 \mathrm{~h}$ (10:00-12:00) with

140 same procedures mentioned above. These males were subjected to four different experimental regimes: (1) one grain of brown rice and one female $(N=13),(2)$ one grain of brown rice $(N=11),(3)$ one female $(N=13)$, or $(4)$ neither brown rice nor a female $(N$ $=14)$. 
145 Analyses

We used Mann-Whitney $U$-tests to examine sexual size differences in their body length and pronotum width. Analysis of covariance (ANCOVA) was used to assess the relationships between body length and leg traits, with particular focus on sexual differences in the slopes of this relationship. The rationale for using ANCOVA was to

150 determine which sex was under higher sexual selection pressure.

The proportions of aggressive behavior in each group were compared using Fisher's exact probability test. For comparisons among more than three groups, sequential Bonferroni methods (Rice 1989) were applied after Fisher's exact probability test at the 5\% significance level. The starvation level or sex of the opponent, which

155 affects the proportion of successfully feeding individuals, was analyzed using a $\log$ linear model. Likelihood ratio tests were used to examine the relationship between the level of starvation and the proportions of chasing and fighting individuals. The starvation level and experimental conditions (i.e. between small males, between large males, and between large and small males), which affect the frequencies of chasing and 160 fighting behavior and the duration of fighting behavior, were analyzed using ANCOVA. 
Binomial tests were used to examine the effect of body size on the outcomes of chasing and fighting behavior. All analyses were conducted using JMP IN version 5 release 5.1.2 software (SAS Institute Inc. 2004).

\section{RESULTS}

Sexual Size Dimorphism in Morphometric Traits

Males were significantly larger than females on all measured traits (Fig. 1, Table 1).

Males also had significantly larger front and middle legs; ANCOVA results indicated that the slopes of the relationships between body length and the linear femur length of the foreleg, the femur width of the foreleg, and the femur length of the middle leg were significantly greater in males than in females (sex effect: see in Table 1; body length effect: femur length of the foreleg, $P<0.001$; femur width of the foreleg, $P<0.001$; femur length of the middle leg, $P<0.001)$. Significant interactions were observed between sex and body length for the femur length and width of the foreleg but not for the

175 femur length of the middle leg (Sex $\times$ Body length interaction: femur length of the foreleg, $P<0.001$; femur width of the foreleg, $P<0.001$; femur length of the middle leg, 
$P=0.465)$, i.e. the femur length and width of the foreleg increased more in males than in females with increases in body length.

We placed two males and two females and examined aggressive behavior between males, between females and between male and female. Aggressive behaviors occurred primarily between males and did not appear to be lethal, nor were any puncture wounds observed. Aggressive behaviors between males tended to occur more frequently at the

185 10-day starvation level compared to 0 days of starvation. We did not observe any aggressive behaviors between females, and we rarely observed aggressive behaviors between males and females (Table 2). Under 10-day starvation, only two males chased a female and on only one occasion each. The proportion of successfully feeding individuals indicated that the sex of the opponent strongly affected male aggression (log

190 linear model; starvation level: $\mathrm{df}=1, \chi^{2}=0.355, P=0.552$; sex of the opponent: $\mathrm{df}=1$, $\chi^{2}=38.431, P<0.001$; Fig. 2). Males which controlled a brown rice allowed females to feed on the rice, meanwhile, they did not allow other males to feed on the rice both under 
0-day and 10-day starvation levels (Fig. 2).

When both males were small, the starvation level and proportions of chasing and fighting were not significantly related (Table 3); however, when both males were large, the proportion of chasing and fighting individuals increased significantly with the severity of starvation (Table 3). When males were of unequal size, the proportion of

200 chasing individuals was not significantly related to starvation level (Table 3); however, the proportion of fighting individuals increased significantly with the severity of starvation (Table 3).

The frequency of chasing behavior was not affected by the level of starvation or by male size relationships (ANCOVA; starvation level: $F=0.48, P=0.492$; experimental conditions: $F=2.161, P=0.127$; Table 3 ). The frequency of fighting individuals increased significantly with the severity of starvation (starvation level: $F=4.22, P<$ 0.05; experimental conditions: $F=1.351, P=0.274$; Table 3 ). The duration of fighting behavior was not affected by the level of starvation or experimental conditions 
(starvation level: $F=0.011, P=0.919$; experimental conditions: $F=0.612, P=0.544$;

210 Table 3).

The proportions of aggressive behavior between large males $(68.8 \%, N=16)$ and between small and large males $(75.0 \%, N=16)$ were significantly higher than that between small males $(23.1 \%, N=13)$ but did not differ significantly from one another (Fisher's exact probability test $P<0.05$ with adjustment by the sequential Bonferroni

215 method). In male-male competition between large and small males, large males won all chasing and fighting events (binomial tests; chasing, starved for 0 days: $N=29, P<$ $0.001 ; 5$ days: $N=26, P<0.001 ; 10$ days; $N=75, P<0.001$; fighting, starved for 5 days: $N=9, P<0.01 ; 10$ days: $N=42, P<0.001)$. Which Is the Main Factor Causing Male Aggressive Behavior: Food or Females?

Aggressive behavior occurred primarily in the presence of food (Fisher's exact probability test $P<0.001)$. The proportions of aggressive behavior in the presence of both food and females $(46.2 \%, N=13)$ and in the absence of females $(54.5 \%, N=11)$ did not differ significantly $(P>0.05$ using Fisher's exact probability test adjusted by the 
sequential Bonferroni method). However, the proportion of aggressive behavior in the absence of food was $0 \%$ regardless of whether a female was present (present: $N=13$; not present: $N=14)$ and varied significantly from treatments with food $(P<0.05)$. In the absence of food, we observed mating in 5 cases of 13 , whereas in the presence of food, mating occurred in 7 cases of 13 .

\section{DISCUSSION}

In many insects, the body size of females is larger than that of males, probably because of a high fecundity advantage for large females (Shine 1988; Honek 1993; Andersson 1994). Teder and Tammaru (2005) showed that females were the larger sex in $>80 \%$ of 158 insect species from a variety of insect orders. However, T. hemipterus exhibits male-biased sexual size dimorphism, in which males are significantly larger than females in body size (Table 1). Sexual size dimorphism is presumably the result of adaptation in response to a difference in the net selection pressures between the sexes (Andersson 1994; Preziosi and Fairbairn 1996; Blanckenhorn 2000, 2005). A larger 
Fairbairn 1997; Blanckenhorn 2005), and the male-biased sexual size dimorphism in $T$. hemipterus appears to be partially related to sexual selection favoring large males, as a larger body size is advantageous in aggressive behavior (both chasing and fighting).

Togo hemipterus males have proportionately larger forelegs than females (Fig. 1).

245 In contrast to the linear regression of femur length of the foreleg on body length, the slope of the linear regression of femur length of the middle leg on body length did not differ significantly between sexes, indicating that the male foreleg traits have developed through sexual selection and serve a distinct function in males, i.e. as "weapons" in male-male competition.

The two aggressive behaviors of T. hemipterus, i.e. chasing and fighting, occurred mainly between males and rarely between females or between males and females (Table 2). However, in other species of Heteroptera, fighting behavior occurs both between females and between males and females (Mitchell 1980; Eberhard 1998; Rodriguez 2000). In general, females are more likely to fight over food than are males because they require more resources to produce eggs. However, T. hemipterus females rarely fought, even when they were starved (Table 2). These results strongly indicate that aggressive 
behavior functions as male-male competition in T. hemipterus.

The proportion of successfully feeding individuals indicated that the sex of the opponent strongly affects male aggressive behavior. Males allowed females to feed (Fig. 2) and then often courted them and sometimes mated. Male T. hemipterus may use food as a nuptial gift, similar to other animal species (reviewed in Thornhill and Alcock 1983; Andersson 1994; Vahed 1998). Males of the lygaeid Stilbocoris natalensis also offer food to females as a nuptial gift (Carayon 1964), although S. natalensis males do not have enlarged forelegs and do not fight one another (Carayon 1964). Additional experimental work is necessary to determine whether $T$. hemipterus indeed uses food as a nuptial gift. Recent study suggested that food may function as a counter-drug against male's toxic seminal substances in T. hemipterus (Himuro and Fujisaki 2010).

We found that a larger body size is advantageous in male-male competition, such as chasing and fighting, indicating that body size is a good predictor of resource-holding power (Parker 1974). We found that escalated fighting frequently occurred even when the difference in the body size of contestants was large. Furthermore, the difference in the body size of contestants had no effect on the duration of fighting behavior in $T$. 
hemipterus. We did not examine the effects of the value of the resource to each contestant, which may have affected the pattern and duration of fighting behavior

275 (Enquist and Leimar 1987). In this assay, the insects were in a closed and limited space.

Thus the frequency and the duration of aggressive behavior would be probably much higher than those in nature. It is needed to investigate the effects of the density of individuals and the size of space on their aggressive behaviors.

Aggressive behaviors occurred primarily when a large male was involved,

280 indicating that the benefit and/or cost arising from the aggressive behavior varies depending on body size. Smaller males may adopt a different strategy in male-male competition, as observed in several other animal species (reviewed in Shuster and Wade 2003).

The proportions of fighting and chasing individuals and the frequency of fighting behavior increased with the severity of starvation (Table 3). Males fought only when food was present, regardless of whether a female was present. Therefore, the presence of food was clearly an extremely important factor in T. hemipterus competition. In contrast, the presence of a female did not appear to be a proximate factor affecting male 
competition; instead, female presence may serve as an important ultimate factor in $T$.

The distribution of females is thought to be primarily affected by resources, whereas the distribution of males should be primarily affected by the availability of females (Bradbury and Vehrencamp 1977; Emlen and Oring 1977). This difference may be attributable to the fact that female reproductive success tends to be limited by

295 resources, whereas male reproductive success tends to be limited by access to females (Bradbury and Vehrencamp 1977; Emlen and Oring 1977). In the field, T. hemipterus feeds on graminaceous seeds, and the distribution and abundance of seeds tend to vary highly in space and time (Solbreck 1978; Solbreck and Pehrson 1979). Himuro (2009) demonstrated that $T$. hemipterus males attract females using sex pheromones, especially

300 when males feed on seeds. Consequently, T. hemipterus males might adopt a kind of resource-defense mating system that would be beneficial because females aggregate near food resources when they are scarce. In contrast, when food resources are abundant, females are more scattered throughout the habitat, forcing males to search for them. Thus, T. hemipterus males may adopt alternative mating strategies depending on the 
305 distribution and abundance of food resources. This hypothesis was supported to some extent by our observation that the proportion of fighting and chasing males increased with increases in the severity of starvation. Moreover, such strategies may vary depending on male body size. 
We thank Dr. T. Nishida and the members of the Laboratory of Insect Ecology, Kyoto University, for valuable advice and discussion of the experiments. This work was supported in part by the 21st Century COE program for Innovative Food and Environmental Studies Pioneered by Entomomimetic Sciences, from the Ministry of 315 Education, Culture, Sports, Science and Technology of Japan (JSPS Grant-in-Aid, No. 19-54183). 


\section{REFERENCES}

Andersson M (1994) Sexual Selection. Princeton University Press, New Jersey.

320 Austad, SN (1983) A game theoretical interpretation of male combat in the bowl and doily spider (Frontinella pyramitela). Anim Behav 31:59-73.

Blanckenhorn WU (2000) The evolution of body size: what keeps organisms small? Q Rev Biol 75:385-407.

Blanckenhorn WU (2005) Behavioral causes and consequences of sexual size dimorphism. Ethology 111:977-1016.

Bradbury JW, Vehrencamp SL (1977) Social organization and foraging in emballonurid bats. III. Mating systems. Behav Ecol Sociobiol 2:1-17.

Burkhardt D, de la Motte I (1988) Big 'antlers' are favoured: female choice in stalk-eyed flies (Diptera, Insecta), field collected harems and laboratory experiments. J Comp Physiol A 162:649-652.

Carayon J (1964) Un cas d'offrande nuptiale chez les Hétéroptères. CR Acad Sci Paris 259:4815-4818.

Eberhard WG (1979) The function of horns in Podischnus agenor (Dynastinae) and 
other beetles. In: Blum MS, Blum NA (eds) Sexual Selection and Reproductive

Eberhard WG (1980) Horned beetles. Sci Am 242:124-131.

Eberhard WG (1998) Sexual behavior of Acanthocephala declivis guatemalana

(Hemiptera: Coreidae) and the allometric scaling of their modified hind legs. Ann Entomol Soc Am 91:863-871.

340 Eberhard WG, Gutiérrez EE (1991) Male dimorphisms in beetles and earwigs and the question of developmental constraints. Evolution 45:18-28.

Emlen DJ, Nijhout HF (2000) The development and evolution of exaggerated morphologies in insects. Annu Rev Entomol 45:661-708.

Emlen ST, Oring LW (1977) Ecology, sexual selection, and the evolution of mating systems. Science 197:215-223.

Enquist M, Leimar O (1987) Evolution of fighting behaviour: the effect of variation in resource value. J Theor Biol 127:187-205.

Fairbairn DJ (1997) Allometry for sexual size dimorphism: pattern and process in the coevolution of body size in males and females. Annu Rev Ecol Syst 28:659-687. 
350 Forslund P (2000) Male-male competition and large size mating advantage in European earwigs, Forficula auricularia. Anim Behav 59:753-762.

Fujisaki K (1980) Studies on the mating system of the winter cherry bug, Acanthocoris sordidus Thunberg (Heteroptera: Coreidae) I. Spatio-temporal distribution patterns of adults. Res Popul Ecol 21:317-331.

355 Fujisaki K (1981) Studies on the mating system of the winter cherry bug, Acanthocoris sordidus Thunberg (Heteroptera: Coreidae) II. Harem defence polygyny. Res Popul Ecol 23:262-279.

Himuro C (2009) Evolutionary ecology research about sexual conflict over reproduction in the seed bug Togo hemipterus (Heteroptera: Lygaeidae). $\mathrm{PhD}$ thesis. University of Kyoto, Kyoto, Japan (in Japanese).

Himuro C, Fujisaki K (2010) Mating experience weakens starvation tolerance in the seed bug Togo hemipterus (Heteroptera: Lygaeidae). Physiol Entomol $35: 128-133$.

Honek A (1993) Intraspecific variation in body size and fecundity in insects: a general relationship. Oikos 66:483-492. 
Maynard Smith J, Price GR (1973) The logic of animal conflict. Nature 246:15-18.

McAlpine DK (1979) Agnostic behavior in Achias australis (Diptera, Platystomatidae) and the significance of eyestalks. In: Blum MS, Blum NA (eds) Sexual Selection and Reproductive Competition in Insects. Academic Press, New York, pp $221-230$.

Miller NCE (1971) The biology of the Heteroptera. EW Classey Ltd, Hampton.

Mitchell PL (1980) Combat and territorial defense of Acanthocephala femorata (Hemiptera: Coreidae). Ann Entomol Soc Am 73:404-408.

Miyatake T (1993) Male-male aggressive behavior is changed by body size difference in the leaf-footed plant bug, Leptoglossus australis, Fabricius (Heteroptera: Coreidae). J Ethol 11:63-65.

Miyatake T (1995) Territorial mating aggregation in the bamboo bug, Notobitus meleagris, Fabricius (Heteroptera: Coreidae). J Ethol 13:185-189.

Miyatake T (1997) Function morphology of the hind legs as weapons for male contests in Leptoglossus australis (Heteroptera: Coreidae). J Insect Behav 10:727-735.

Moore AJ, Wilson P (1993) The evolution of sexually dimorphic earwig forceps: social 
interactions among adults of the toothed earwig, Vostox apicedentatus. Behav Ecol 4:40-48.

Otte D, Stayman K (1979) Beetle horns: Some patterns in functional morphology. In:

Insects. Academic Press, New York, pp 259-292.

Parker GA (1974) Assessment strategy and the evolution of fighting behaviour. J Theor

Biol 47:223-243.

Preziosi RF, Fairbairn DJ (1996) Sexual size dimorphism and selection in the wild in the waterstrider Aquarius remigis: body size, components of body size and male mating success. J Evol Biol 9:317-336.

Radesäter T, Halldórsdóttir H (1993) Two male types of the common earwig: male-male competition and mating success. Ethology 95:89-95.

Rice WR (1989) Analyzing tables of statistical tests. Evolution 43:223-225.

395 Rodriguez SRL (2000) On the fore legs of seed bugs (Heteroptera: Lygaeidae):

aggression and allometric scaling in Scolopostethus affinis Schilling. J Kansas

Entomol Soc 73:6-10. 
SAS Institute Inc (2004) JMP Start Statistics, 3rd ed. SAS Institute Inc, Cary, NC, USA.

Schuh RT, Slater JA (1995) True Bugs of the World (Hemiptera: Heteroptera):

400

Classification and Natural History. Cornell University Press, New York.

Shine R (1989) Ecological causes for the evolution of sexual dimorphism: a review of the evidence. Q Rev Biol 64:419-461.

Shine R (1988) The evolution of large body size in females: a critique of Darwin's

"Fecundity advantage" model. Am Nat 131:124-131.

405 Shuster S, Wade M (2003) Mating systems and strategies. Princeton University Press,

Princeton, New Jersey.

Solbreck C (1978) Migration, diapause, and direct development as alternative life

histories in a seed bugs, Neacoryphus bicrucis. In: Dingle H (ed) Evolution of

Insect Migration and Diapause. Springer-Verlag, New York, Heidelberg, Berlin,

410 pp 195-217.

Solbreck C, Pehrson I (1979) Relations between environment, migration and reproduction in a seed bug, Neacoryphus bicrucis (Say)(Heteroptera: Lygaeidae).

Oecologia 43:51-62. 
Teder T, Tammaru T (2005) Sexual size dimorphism within species increases with body size in insects. Oikos 108:321-334.

Thornhill R, Alcock J (1983) The Evolution of Insect Mating Systems. Harvard University Press, Cambridge, Massachusetts.

Tomokuni M, Yasunaga T, Takai M, Yamashita I, Kawamra M, Kawasawa T (1993) A field guide to Japanese bugs_-Terrestrial heteropterans. Zenkoku Noson Kyoiku Kyokai, Publishing Co, Ltd, Tokyo, Japan (in Japanese).

Vahed K (1998) The function of nuptial feeding in insects: a review of empirical studies.

Biol Rev 73:43-78.

Wells MS (1988) Effects of body size and resource value on fighting behaviour in a jumping spider. Anim Behav 36:321-326.

425 Wilkinson GS, Dodson GN (1997) Function and evolution of antlers and eye stalks in flies. In: Choe JC, Crespi BJ (eds) The Evolution of Mating Systems in Insects and Arachnids. Cambridge University Press, Cambridge, pp 310-328. 


\section{Tables}

Table 1. Measurements of morphometric traits (mean $\pm 1 \mathrm{SE})$ of Togo hemipterus males $(N=254)$ and females $(N=259)$ in the field

\begin{tabular}{lccc}
\hline \multicolumn{1}{c}{ Morphometric trait } & Males & Females & $P$-value \\
\hline Body length (mm) & $5.94 \pm 0.02$ & $5.90 \pm 0.02$ & $<0.05^{\dagger}$ \\
Pronotum width (mm) & $1.31 \pm 0.01$ & $1.21 \pm 0.00$ & $<0.001^{\dagger}$ \\
Femur length of foreleg (mm) & $1.87 \pm 0.01$ & $1.62 \pm 0.01$ & $<0.001^{\dagger \dagger}$ \\
Femur width of foreleg (mm) & $0.52 \pm 0.00$ & $0.47 \pm 0.00$ & $<0.001^{\dagger \dagger}$ \\
Femur length of middle leg (mm) & $1.55 \pm 0.01$ & $1.46 \pm 0.00$ & $<0.001^{\dagger \dagger}$
\end{tabular}

$\dagger P$-values refer to Mann-Whitney $U$-tests.

$\dagger \dagger P$-values refer to ANCOVA (Sex effect) 
Table 2. Proportions of aggressive behavior between males, between females, and between males and females under two levels of starvation in T. hemipterus

\begin{tabular}{lccc}
\hline & \multicolumn{3}{c}{ Proportion of aggressive behavior (\%) } \\
\cline { 2 - 4 } Starvation level & Between males & Between females & Between males and females \\
\hline 0 days & $18.2(11) \mathrm{ab}$ & $0(11) \mathrm{b}$ & $0(11) \mathrm{b}$ \\
10 days & $61.5(13) \mathrm{a}$ & $0(13) \mathrm{b}$ & $15.4(13) \mathrm{ab}$ \\
\hline
\end{tabular}

Numbers in parentheses indicate sample size.

Fisher's exact probability test, $P<0.001$.

Different letters indicate significant differences $(P<0.05)$ using Fisher's exact probability tests (adjusted by the sequential Bonferroni method). 
Table 3. Effect of starvation on aggressive behavior between two small males, between two large males, or between one large and one small male of T. hemipterus

\begin{tabular}{|c|c|c|c|c|}
\hline \multirow[b]{2}{*}{ Two small males } & \multicolumn{3}{|c|}{ Starvation level } & \multirow[b]{2}{*}{$P$-value } \\
\hline & 0 days & 5 days & 10 days & \\
\hline Proportion of chasing individuals (\%) & $6.3(16)$ & $38.5(13)$ & $23.1(13)$ & 0.238 \\
\hline Frequency of chasing behavior & $18(1)$ & $7.8 \pm 1.5(5)$ & $7.0 \pm 3.6(3)$ & \\
\hline Proportion of fighting individuals (\%) & $6.3(16)$ & $30.1(13)$ & $23.1(13)$ & 0.232 \\
\hline Frequency of fighting behavior & $2.0(1)$ & $1.5 \pm 0.3(4)$ & $7.7 \pm 1.8(3)$ & \\
\hline Duration of fighting behavior (s) & $9.2 \pm 3.8(2)$ & $12.1 \pm 1.7(6)$ & $8.0 \pm 1.0(23)$ & \\
\hline \multicolumn{5}{|l|}{ Two large males } \\
\hline Proportion of chasing individuals (\%) & $7.1(14)$ & $37.5(16)$ & $56.3(16)$ & $<0.01$ \\
\hline Frequency of chasing behavior & $1.0(1)$ & $6.0 \pm 1.3(6)$ & $3.0 \pm 0.6(9)$ & \\
\hline Proportion of fighting individuals (\%) & $0(14)$ & $31.3(16)$ & $56.3(16)$ & $<0.01$ \\
\hline Frequency of fighting behavior & $0(0)$ & $3.4 \pm 1.4(5)$ & $2.3 \pm 0.6(9)$ & \\
\hline Duration of fighting behavior (s) & - & $7.0 \pm 0.9(17)$ & $8.6 \pm 1.1(20)$ & \\
\hline \multicolumn{5}{|l|}{ One large and one small male } \\
\hline Proportion of chasing individuals (\%) & $57.1(14)$ & $46.2(13)$ & $68.8(16)$ & 0.385 \\
\hline Frequency of chasing behavior & $3.6 \pm 1.4(8)$ & $4.5 \pm 2.2(6)$ & $6.8 \pm 2.0(11)$ & \\
\hline Proportion of fighting individuals (\%) & $0(14)$ & $23.1(13)$ & $50(16)$ & $<0.01$ \\
\hline Frequency of fighting behavior & $0(0)$ & $3.0 \pm 2.0(3)$ & $6.4 \pm 2.6(8)$ & \\
\hline Duration of fighting behavior (s) & - & $6.7 \pm 1.0(9)$ & $7.9 \pm 0.8(42)$ & \\
\hline
\end{tabular}

Values are mean \pm 1 SE (sample sizes).

$P$-values refer to likelihood ratio tests. 


\section{Figure captions}

Figure 1. Relationships between body length and leg traits (femur length of foreleg, femur width of foreleg, and femur length of middle leg) of males (closed symbols) and females (open symbols) of Togo hemipterus.

Figure 2. The proportion of successfully feeding males and females of T. hemipterus at two levels of starvation ( 0 and 10 days). Bars indicate \pm 1 SE. 

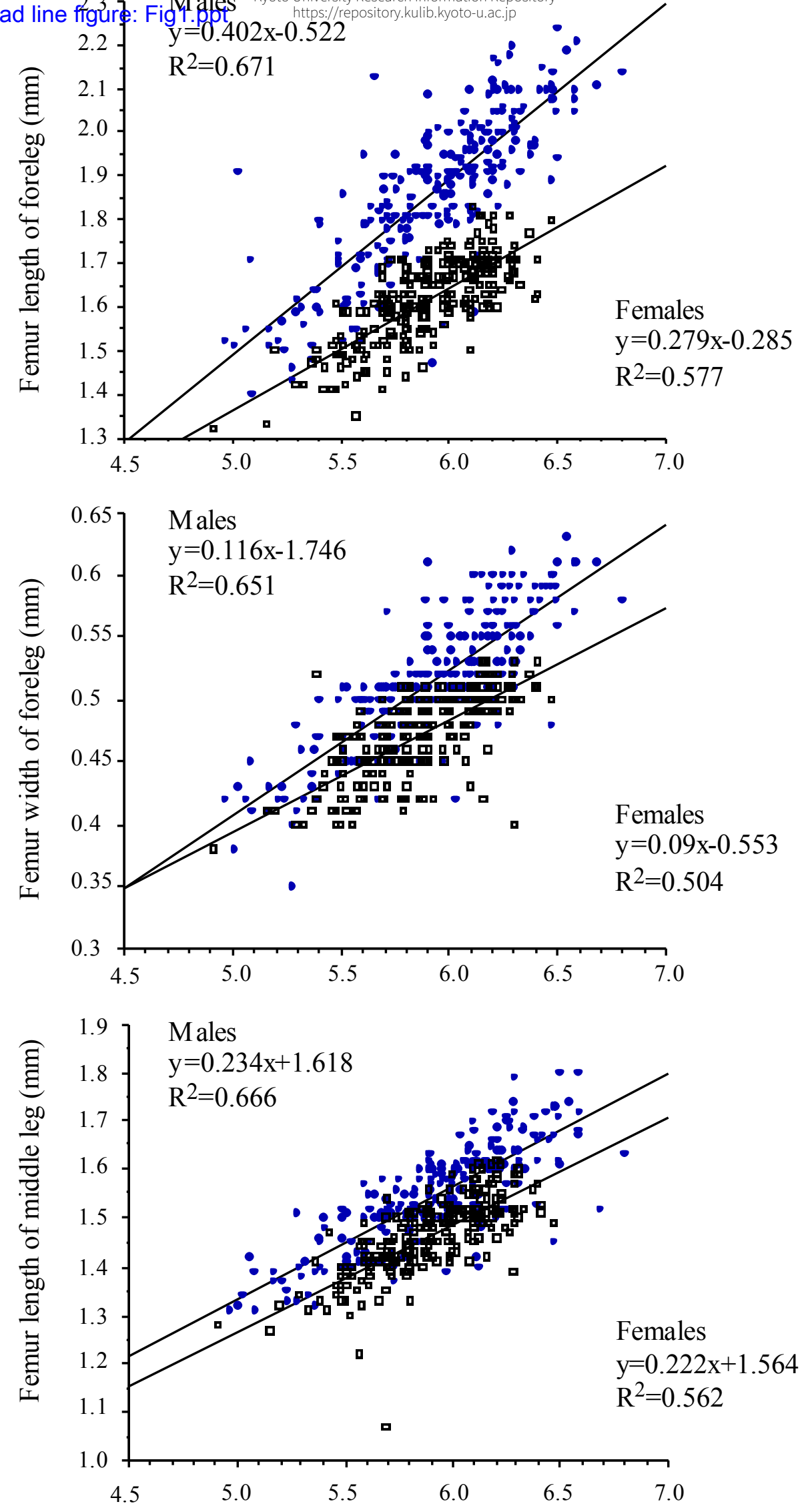

Body length (mm) 


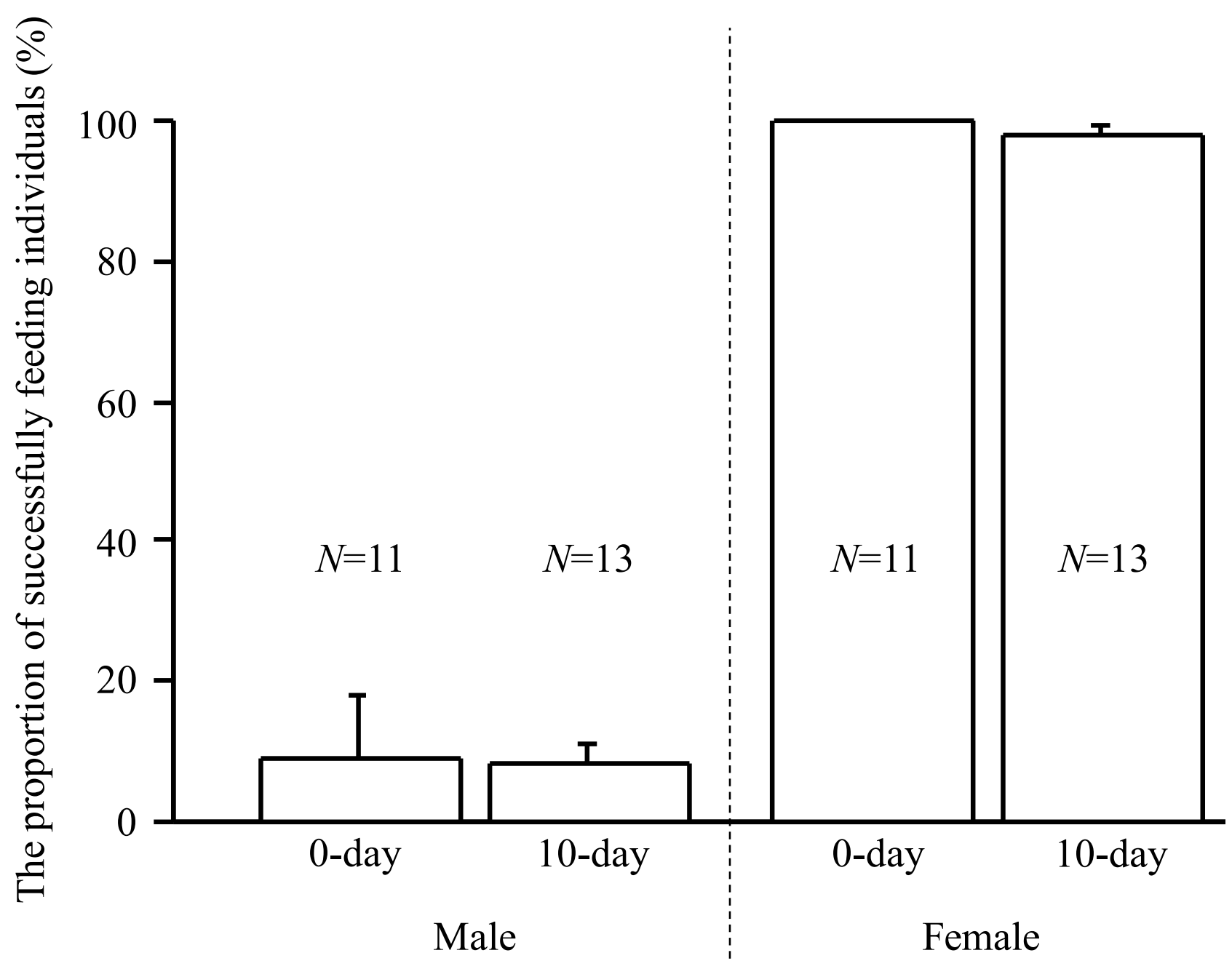

